\title{
The growing importance of oceanic moisture sources for continental precipitation
}

\author{
Luis Gimeno $\mathbb{D i D}^{1 凶}$, Raquel Nieto iD $^{1}$ and Rogert Sori ${ }^{1,2}$
}

The precipitation that falls on the continents defines the extent and nature of terrestrial ecosystems and human activity in them, all of which are adapted to and maintained by present-day precipitation. In essence, precipitation is supplied by moisture that either comes directly from the ocean, or is subsequently recycled from the continents themselves. Both the processes that control evaporation and the main mechanisms of moisture transport clearly differ between the ocean and the continent, thus within the context of a changing climate, it may be expected that the relationship between precipitation of oceanic and terrestrial origin varies globally and regionally, as will the influence of these two basic components of total precipitation on global and regional precipitation trends, especially in tropical regions. We describe an approach based on a Lagrangian technique for estimating the precipitation in a target region given the proportions of moisture transported from the two sources (ocean and continent) to reveal that the percentage of precipitation of oceanic origin has increased globally in the current climate (1980-2016). The greatest observed rate of increase is in the tropical regions; furthermore, the trends of precipitation in these regions are controlled by trends in precipitation for which the source of moisture is the ocean.

npj Climate and Atmospheric Science (2020)3:27; https://doi.org/10.1038/s41612-020-00133-y

\section{INTRODUCTION}

One of the points of greatest uncertainty in ongoing investigations of climate change is the determination of whether global precipitation over the continents has changed with global warming, together with the regional patterns of any changes ${ }^{1}$. Long data sets of more than a century, which would allow us to control for the effects of low-frequency climate oscillation, tend to be incomplete for large continental areas, and this limits the extent of the possible analysis. Use of a shorter period limited to the last five decades could improve the spatial coverage thanks to the use of estimated precipitation derived from satellite data, but this has the inconvenience of the short period used, in terms of climatic variability ${ }^{2}$. The increase in the availability of precipitation databases at grid scale, with or without the support of physical models, has not been of much help in clearing up these questions, given some divergent results in regional trends ${ }^{3}$. From the conclusions of the last IPCC report ${ }^{\top}$ and since 1950, which includes the post-satellite period, there is a moderate level of confidence in the precipitation changes averaged over global land areas, with precipitation products showing significant negative trends in some cases and not in others. At the regional level, according to latitudinal band there is a high degree of confidence in the growing trend of precipitation in the mid-latitudes of the northern hemisphere but low confidence in other regions, due either to a lack of data or a general lack of quality of the data, although there is some confidence in the growing trend of tropical precipitation seen since the mid-1990s. To improve confidence in these estimated precipitation trends, it is useful to examine the coherence of these changes with those seen in other components of the hydrological cycle directly related to precipitation $^{4}$, and for which these changes have a physical interpretation linked to increased temperature ${ }^{5}$. Moisture transport and changes in the source-sink relationship ${ }^{6,7}$ can play a very important role here, which at a large scale allows the analysis of variations in the relative importance of oceanic sources versus terrestrial sources in continental precipitation ${ }^{8,9}$

Despite the inherent complexity of the hydrological cycle with the large number of physical processes involved, essential theoretical considerations suggest that the percentage of precipitation of oceanic origin could increase with global warming, and that this trend could have been observable in recent decades given the recorded increase in global temperature. Basic considerations of thermodynamics and energetics suggest that the patterns of mean atmospheric moisture content, precipitation and its extremes, and evaporation-minusprecipitation must grow as the globally averaged surface temperature increases ${ }^{10-13}$. In the absence of major changes in atmospheric circulation, this in turn implies greater transport from divergent to convergent regions. Because the main divergent regions are located in subtropical oceans and the continents are generally convergent regions, the contribution of precipitation of oceanic origin will increase. The single thermodynamic scaling of the moisture convergence, otherwise known as the dry gets drier, wet gets wetter mechanism ${ }^{14,15}$ and the extended scaling to incorporate horizontal gradients of change in temperature and fractional changes in relative humidity ${ }^{16}$ both lead to a robust drying tendency over the continents at almost all latitudes, meaning that the extent of these dry regions will increase ${ }^{17}$. Furthermore, limitations in the availability of soil moisture influence the evaporation of moisture of terrestrial origin, reducing the importance of terrestrial vs oceanic precipitation. In all these considerations, it is assumed that the global increase in temperature implies no major change in the general circulation of the atmosphere, which could result in changes to precipitation different from those expected due to thermodynamic criteria alone. These theoretical considerations are supported by recent numerical simulations for past and future climates compared with the present, with decreases in global mean recycling ratios of the 
order of $2-3 \%$ for each degree of temperature ${ }^{18}$, although it has never been claimed that this is in fact happening in the present climate, nor has its magnitude been established. The quantification of these changes constitutes the first objective of this paper.

The observed and expected changes in the distribution of global rainfall with the increase of temperature are uncertain, although solid physical arguments ${ }^{5,12,19}$, modelling studies for future climates ${ }^{20,21}$, and some observational evidence ${ }^{5,22,23}$ all indicate drying in drier subtropical regions and increased precipitation in the inter-tropical convergence zone. In these tropical regions, where the relationship between moisture transport and precipitation is more direct ${ }^{24}$, it can be hypothesised that where the precipitation is enhanced or reduced, the oceanic contribution to it is increased or decreased, respectively. This question forms the second objective of the paper.

\section{RESULTS}

Changes in the percentage of precipitation of oceanic origin

This study estimates the oceanic and terrestrial components of precipitation on a global grid, based on application of the optimal integration time, as calculated by Nieto and Gimeno ${ }^{25}$. This optimal integration time is defined by first calculating the humidity transported to a grid point over a given time, from anywhere, and then finding the time for which the resulting precipitation best matches observational or reanalysis products. We use a Lagrangian approximation to calculate the humidity that results in precipitation at each grid element from two sources, namely the entire ocean area (ocean component of the precipitation, now called PLO) and the entire land area (land component, now called PLT). The sum of the two components (PL) is a faithful representation of the precipitation from ERA-Interim reanalysis ${ }^{26}$, now called PERA-I (Fig. 1a, b) and its trends (Fig. 1c, d) for most parts of the world, with excellent inter-annual correlation between PL and PERA-I (Fig. 1e). There are areas of low rainfall, such as the Sahara Desert, California, and southern South America, where the correlation is weaker. Whatever the optimal integration time and precipitation database chosen as described in Nieto and Gimeno $^{25}\left(\right.$ ERA-I $^{26}$, GPCP $^{27,28}$ or MSWEP ${ }^{29}$ ), a precipitation pattern $(\mathrm{PL})$ is produced similar to ERA-I (see Fig. 1 and Supplementary Figs. 1 and 2 to compare), which contains the data used to feed the Lagrangian model; thus the results of this approach are constrained by the limitations of ERA-I. Analysis by latitude band (Fig. 1f) shows a slight underestimation of PL compared with PERA-I before the year 2000, and a slight overestimation since then, which derives mainly from the extratropical latitudinal band of the southern hemisphere, the adjustment being much better for tropical and extratropical regions of the northern hemisphere, which account for the majority of the continental effects. (a)

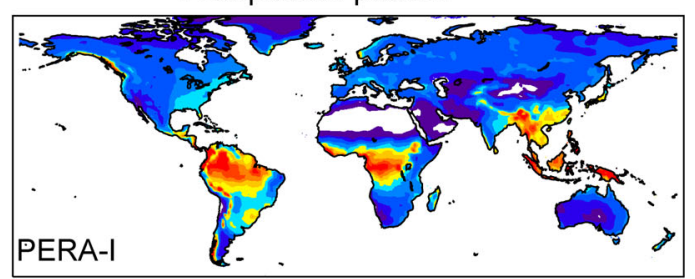

(b)

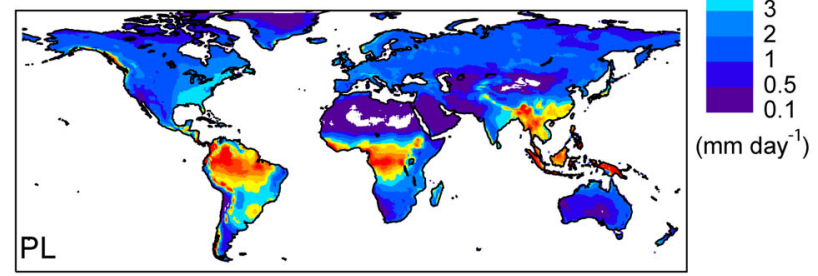

(e) Significant correlation between PERA-I and PL

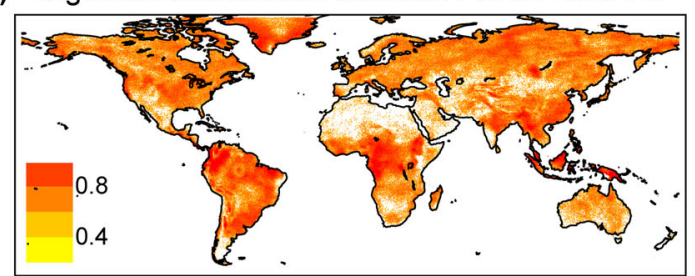

(f)

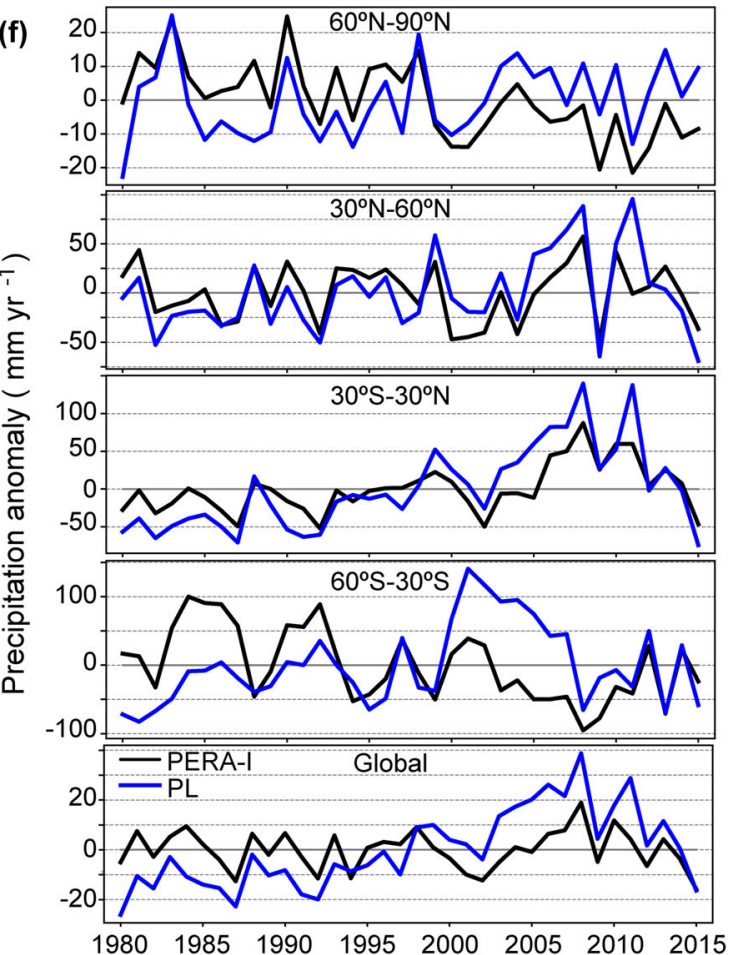

Fig. 1 Comparison between ERA-Interim versus the reconstructed Lagrangian precipitation. a, b Spatial pattern of annual mean precipitation from PERA-I (a) and PL (b). c, d Statistically significant trends $(p<0.05)$ for PERA-I (c) and PL (d). e Spatial distribution of significant correlation coefficients $(p<0.05)$ between PERA-I and PL. $\mathbf{f}$ Time series of precipitation anomalies averaged over land areas relative to the whole period of study $1980-2015$ for the global case and for four latitudinal bands for PERA-I and PL. 
(a)

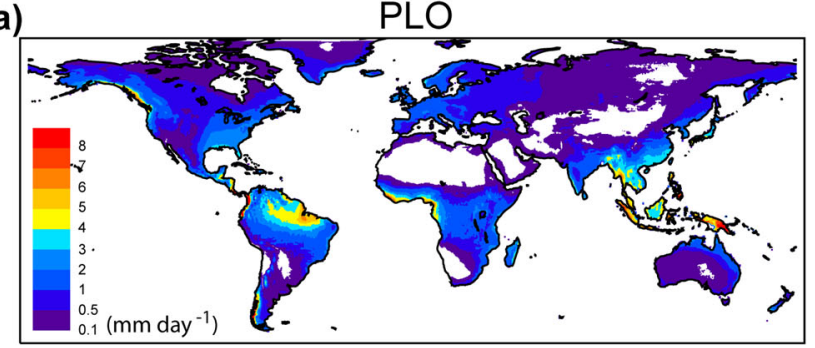

(c)

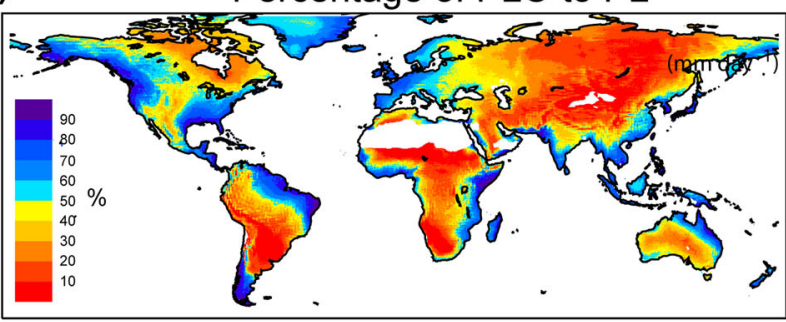

(d)

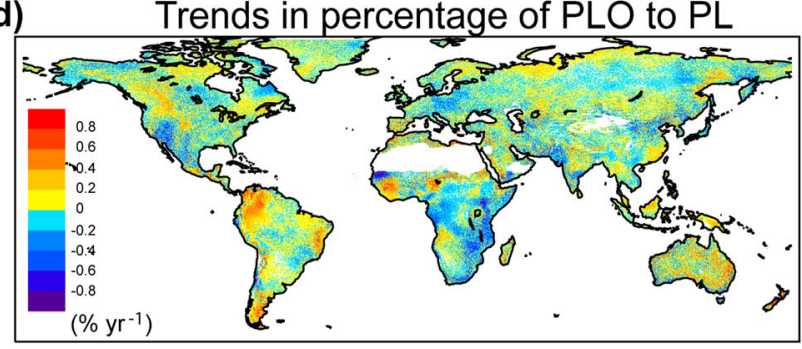

(e)

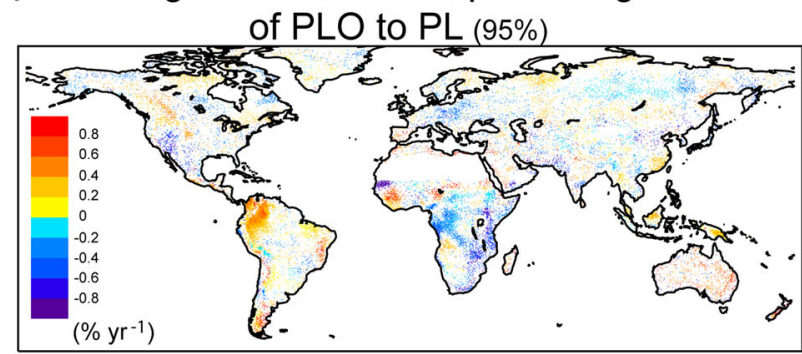

(b)

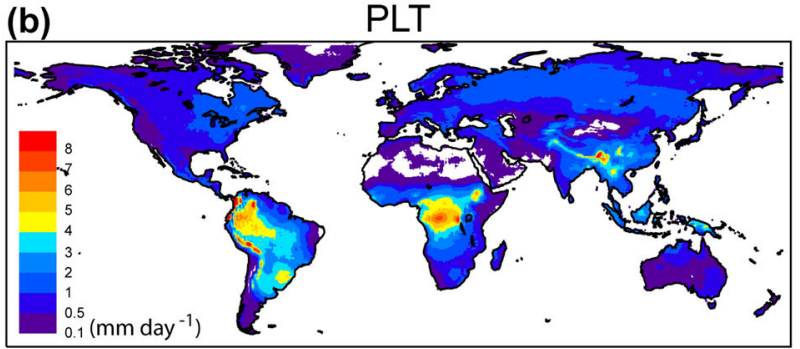

(f)
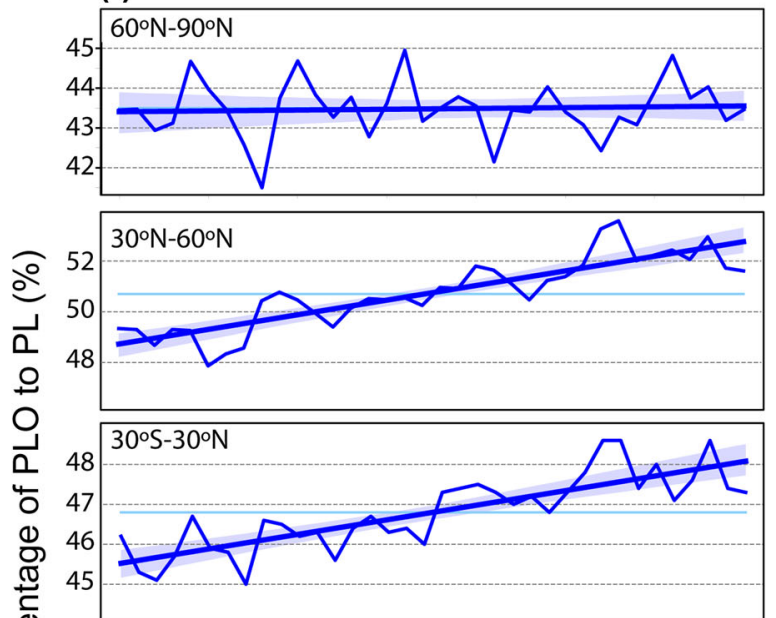

ญ.

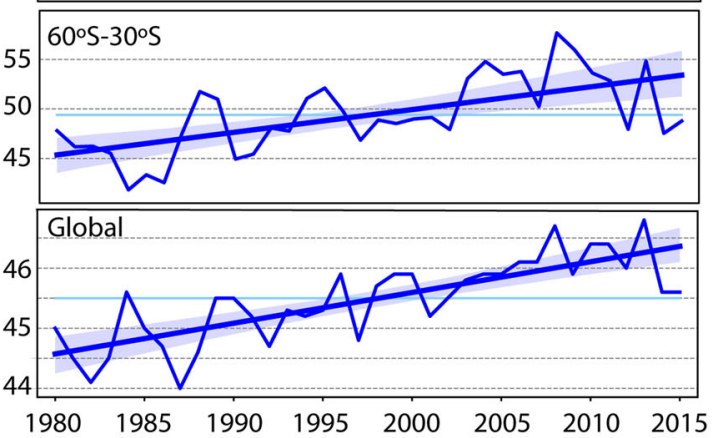

Fig. 2 Distributions of the ocean and terrestrial components of precipitation. a, b Spatial patterns of annual precipitation for PLO (a) and PLT (b). c-e Spatial pattern of the total percentage contribution of PLO to the PL (c) and the gridded annual trends (d, e). $\mathbf{f}$ Interannual variations and trends in the percentage contribution of PLO to PL for the global case and for four latitudinal bands. The horizontal dark blue line shows the mean PLO percentage in each case. The 95 percent confidence interval for the trends are indicated using the shaded bands.

The climatological patterns of PLO, PLT and the percentage of ocean precipitation, (Fig. $2 \mathrm{a}-\mathrm{c}$ ) show a distribution that is highly recognisable, including a maximum precipitation of terrestrial origin in the moisture sinks of the Congo and the Amazon basin, and a strongly negative gradient of percentage of ocean precipitation related to distance from the coast ${ }^{3,23}$. The effect of orographically limited transport of moisture from the ocean, and thus a reduction of the oceanic contribution to precipitation is clearly observed in the Indian subcontinent. The strong transport of oceanic moisture linked to storm tracks and atmospheric rivers, or atmospheric rivers and low level jets, can clearly be seen in the large oceanic contribution to the precipitation in the west of the European continent or the Eastern coast of North America, respectively. The global percentage of oceanic precipitation as derived from our methodology has an average of $45.5 \%$, a value lower than that found by Findell et al. ${ }^{18}$, which was just over $60 \%$. The reason for this is the different length scale used here, i.e., the whole world, which causes an increase in the recycling values obtained using other approaches and limited length scales. Findell et al. ${ }^{18}$ used simulations of historical and future climate using the model GFDL-ESM2 $\mathrm{G}^{30,31}$ and the water tracking algorithm WAM2layers ${ }^{32}$. The very different methodologies used here do not permit direct comparison with the values obtained by Findell et al. ${ }^{18}$, but it is still useful to compare the trends.

At the global scale, the percentage of oceanic precipitation shows statistically significant growth $(p<0.05)$ at a rate of $0.51 \%$ per decade, with the highest growth in tropical regions between 30 degrees north and 30 degrees south $(1.15 \%$ per decade; Fig. $2 \mathrm{f})$. The global increase represents a rise of about $1.6 \%$ with each degree of global temperature, based on a global ERA-I temperature increase of about 4.5 tenths of a degree over the period $1980-2016^{33}$. These results are of a similar order to those calculated for past and future climate by Findell et al. ${ }^{18}$, who suggested an equivalent figure of between $2-3 \%$. Considering the bias of ERA-I in representing the precipitation variability in some regions (see the methods section), the same analysis was also 
performed by removing those regions in each latitudinal band where there were disagreements in the sign of the precipitation trends between ERA-interim and other non-reanalysed data bases $\left(\mathrm{CRU}^{34}\right.$; GPCP) (full results are included in Supplementary Fig. 3). As envisaged, there are some differences in the percentages obtained with and without these regions, although in general terms the main results are not very different, with the best matches between series for the whole globe (Pearson correlation coefficient $r=0.92$ statistically significant, $p<0.05)$ and the tropical band ( $r=0.93$ statistically significant, $p<0.05$ ), although the average percentage is slightly (about $2.5 \%$ ) lower. There are no significant differences $(p<0.05)$ in the trends in percentage precipitation of oceanic origin for the whole globe $(0.7 \% /$ decade), but this figure is significant higher for the tropical band $\left(30^{\circ} \mathrm{N}-30^{\circ}\right.$ $\mathrm{S})$, at $1.7 \%$ /decade. The trends in the Northern Hemisphere extratropical bands do not appear when the non-matching regions are removed.

The trends are not significant everywhere (Fig. 2d, e), but they are widespread in tropical areas, with a significant decrease in the percentage of oceanic precipitation at the Indian coast, and an increase for the Pacific and Atlantic coast except for the Congo Basin. There are not many such areas in the extratropics; for instance there are some significant decreases in central Europe and parts of North America, in partial agreement with the results of Dirmeyer and Brubaker ${ }^{35}$, who found an increasing trend in the recycling ratio in spring and autumn over North America and Europe. However, this result must be interpreted with some caution, given that Dirmeyer and Brubaker ${ }^{35}$ estimated the fraction of precipitation with local origin at a grid scale, whereas in our case we estimate the fraction of precipitation at a grid point whose origin is the whole of the land/ocean component. Changes in the percentage of ocean precipitation are due to changes in the relationship between the oceanic and terrestrial components of precipitation, but it is interesting to consider which of these two dominates the changes.

Oceanic vs terrestrial origin of the precipitation trends

The linear regression of PERA-I against the ratio of PLO to PLT (Fig. 3a) reveals those areas where the oceanic or terrestrial component dominates the interannual variability of the precipitation. Positive/negative regression coefficients show areas dominated by the oceanic/terrestrial component of precipitation, with the highest values indicating regions with the highest dependence. Those areas where the regression is statistically significant at $95 \%$ are shaded in light grey (Fig. 3b). The pattern is in fact quite similar to the pattern of percentage of oceanic precipitation (Fig. $2 \mathrm{c}$ ), with these results being highly consistent with the sinks of the main sources of moisture for continental precipitation $^{8,9}$, thus the precipitation of oceanic origin dominates the interannual variability of the precipitation in the sink regions for the North Atlantic and North Pacific sources (Western Europe, both North American coasts, and Northeastern South America). The terrestrial sources do the same for the sink regions where the source is the South Atlantic (Atlantic coast of South America and South Africa and the Sahel region), and to a lesser extent the Indian Ocean (Eastern Sahel and Southeastern Australia) and the two interior regions of the Amazon and Congo basins. The interior regions of the Asian continent (regions north of $40^{\circ} \mathrm{N}$ and east of $60^{\circ} \mathrm{E}$ ) without preferential sources of moisture are thus dominated by recycling.

There is very good agreement between the regions showing trends in PLO and PLT (Fig. 3c, d), such that where one shows an increase, so does the other, with a few exceptions such as Australia, for example. There are almost no regions where the sign of the trend differs between PLO and PLT. This indicates that the trends are dominated by changes in circulation that favour more unstable (increasing)/ stable(decreasing) conditions. The regions of significant trend are practically identical when optimal integration times are used ${ }^{25}$ for ERA-I, GPCP or MSWEP, and coincide with the regions of significant trends in ERA-I, which comprise the data that feed FLEXPART ${ }^{36,37}$ (FLEXible PARTicle dispersion model), the Lagrangian transport and dispersion model on which the approach is based and which is highly appropriate for the simulation of atmospheric transport. The agreement with MSWEP precipitation trends is greater than that with GPCP, with discrepancies in trends in central equatorial Africa, an area in which it is difficult to estimate which precipitation product is the more appropriate due to the limited availability and variable quality of rain gauge data ${ }^{3,38,39}$.

The results also show a clear relationship between the trends in the percentage of ocean precipitation (Fig. 2d) and PERA-I, with annual values correlating significantly at $95 \%$ (Pearson correlation coefficient of 0.37 ), this effect being fundamentally responsible for

(a) Regression coefficients PERA-I vs. PLO/PLT

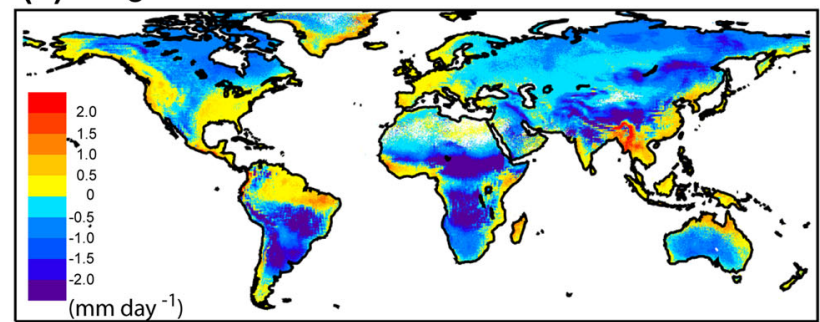

(c) Significant trends of PLT (95\%)

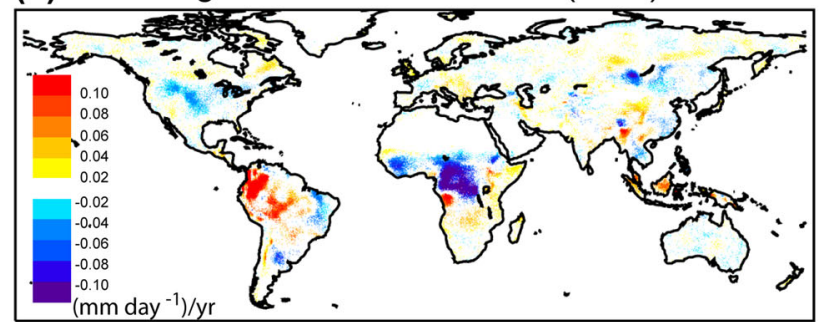

(b)

Significant (95\%) grid points of a)

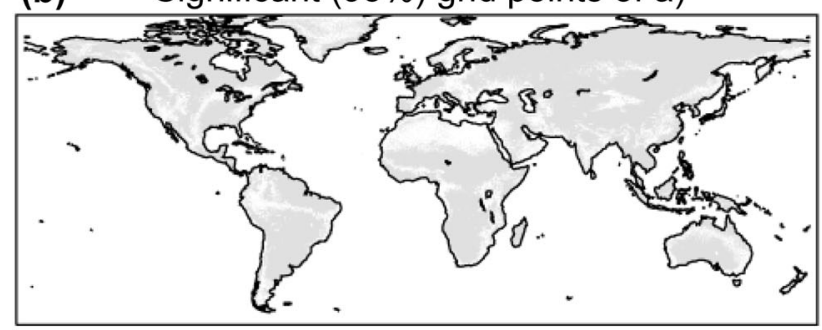

(d)

Significant trends of PLO (95\%)

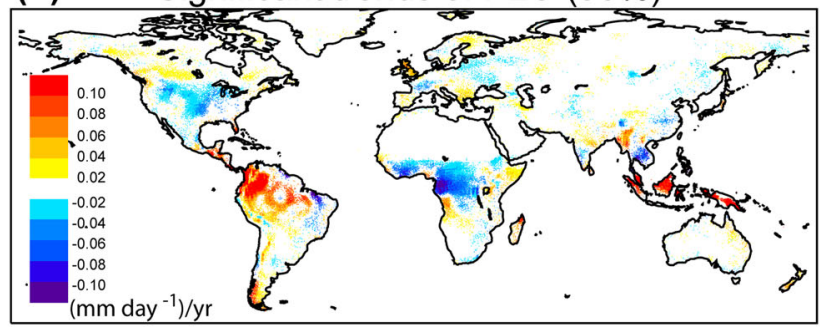

Fig. 3 Regression of PERA-I against the ratio of PLO to PLT and trends of PLO and PLT. a Spatial distribution of the interannual regression coefficients (mm/day) between PERA-I and the ratio of PLO to PLT. b Statistically significant trends of PLT $(p<0.05)$. $\mathbf{c}$, d Statistically significant trends of PLT and PLO. 
(a)

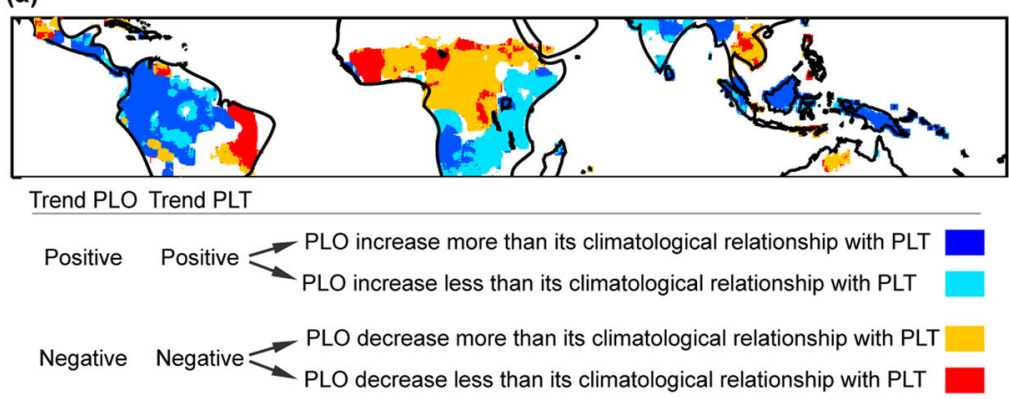

(b)

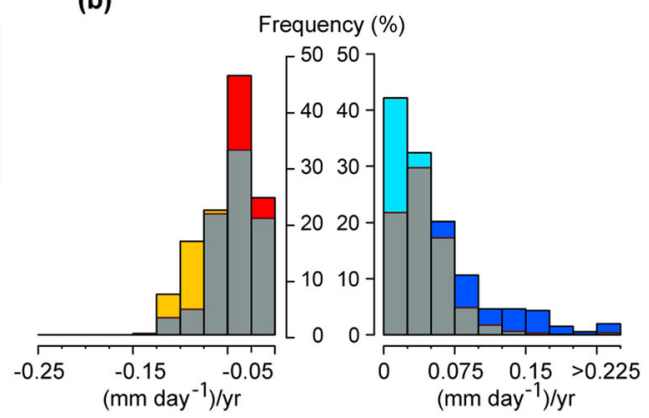

Fig. 4 Relationship between tropical trends in PLO and PLT. a Tropical region $\left(30^{\circ} \mathrm{N}-30^{\circ} \mathrm{S}\right)$ where PERA-I shows significant trends and PLO and PLT grow and decrease synchronously. Dark (light) blue colours indicate where PLO and PLT increase but PLO increases (decreases) more than its climatological relationship with PLT, and dark (light) red colours indicate where both precipitation components decrease but PLO increases (decreases) more than its climatological relationship with PLT. b Histogram of PERA-I trend frequencies for the four different areas defined in a. Time period 1980-2015.

the significant correlation in the tropical band $\left(30^{\circ} \mathrm{N}-30^{\circ} \mathrm{S}\right)$, with a correlation coefficient of 0.70 (significant at 99\%). This finding implies that, assuming the relationship remains stationary, the greater the global rainfall, the greater the percentage of ocean precipitation. This is fundamentally due to the positive correlations seen for the American Pacific coast, the Indo-Pacific Islands, and the Congo Basin. In any case, correlations between PERA-I and the percentage of ocean precipitation cannot be used to distinguish whether the cause of this strong correlation comes from variations in the oceanic or terrestrial precipitation components, as for the rate between PLO and PLO + PLT. The strong correlation could be controlled by changes with the same sign in both PERA-I and PLO, or changes with opposite sign in both PERA$I$ and PLT. Thus it is convenient to analyse the ratio of increase to decrease between PLO and PLT in those regions where there is a trend in PERA-I, especially in the tropics where the relationship between moisture transport and precipitation is the strongest; this is also the region where the majority of global precipitation falls, and its conditions are often used to represent those of the climate system as a whole ${ }^{40}$.

As previously stated, there is almost no discrepancy in the trends of PLO and PLT, in that both grow and decrease synchronously over most of the globe, thus there are 4 possibilities for the nature of each trend, namely:

Option 1: PLO and PLT increase, but PLO increases more than its climatological relationship (averaged for the period of analysis) with PLT

Option 2: PLO and PLT increase, but PLO increases less than its climatological relationship with PLT

Option 3: PLO and PLT decrease, but PLO decreases more than its climatological relationship with PLT

Option 4: PLO and PLT decrease but PLO decreases less than its climatological relationship with PLT

Figure $4 \mathrm{a}$ indicates those regions where the tropical PERA-I shows a significant trend (Fig. 1c) for each subset. Visual inspection seems to suggest that the two components grow in regions of precipitation increase, showing maximum growth when the oceanic component grows more than the terrestrial one; for regions of decreasing PERA-I both components decrease, with the maximum decrease occurring when the oceanic component decreases more than the terrestrial one. This finding seems especially applicable in the tropics. A histogram of trend frequencies for grid elements with significant positive and negative PERA-I trends in the tropics (Fig. 4b) shows that the greatest positive precipitation trends apply for Option 1 and the greatest negative trends apply for Option 3. Distributions of trend frequencies for the 4 options were significantly different when using a z-test with a $95 \%$ confidence level, and the differences in mean precipitation trend for Options 1-4 are significant when using a t-student test with a $95 \%$ confidence level.

Given the important role of soil-atmosphere exchanges in the modulation of the hydrological cycle over the continents ${ }^{41}$, another similar analysis was undertaken but this time the tropical band was divided into water- and energy-limited regions ${ }^{42}$ (Fig. 5a). These results confirm that the previous finding holds regardless of whether the region is water- or energy-limited (Fig. 5b), suggesting also the impact of rising temperatures on the increasing importance of oceanic evaporation as a source of continental precipitation ${ }^{18}$. This is in alignment with previous work, in which wet and dry periods in the main global waterlimited vegetated regions were shown to be triggered by conditions external to them ${ }^{43}$. Furthermore, increased trends in the oceanic component of the precipitation transported towards energy-limited regions such as the Amazon and the Congo basins highlight the growing importance of atmospheric moisture transport from the oceans towards strongly recycling ecosystems ${ }^{44,45}$. Among other findings were that in water-limited regions in the northern hemisphere mid-latitudes, the oceanic impact on precipitation is relatively weak, whereas over tropical continents where the moisture is easily transported, the oceanic impact is more dominant ${ }^{46}$.

Detailed analysis of trend anomalies of PLO and PLT was performed in consideration of the climatological oceanic and terrestrial moisture sources for 4 homogeneous tropical subregions, representing the 4 options for the PLO-PLT trend relationships. These were Central Equatorial Africa, Amazonia, northeast Brazil, and the eastern part of the African continent (Fig. 6a, green line). Air masses over these regions were tracked backwards in time considering the optimum residence time of the water vapour as obtained by Nieto and Gimeno ${ }^{25}$. The vertical integration of the values of $(E-P)>0$ was considered as a means of identifying the most important oceanic and terrestrial moisture sources (green and brown areas respectively in Fig. 6a). Then, the series of PLO and PLT were calculated by a similar forward analysis described for the global oceanic and continental source regions. As shown above, Amazonia and the eastern part of Africa are characterised by a common increase of PLO, but the oceanic component increases more with respect to PLT in the former (Fig. 4). In agreement, the trend anomalies of the ratio of PLO to PLT (Fig. 6b) reveal a positive (negative) slope for Amazonia (eastern Africa). In Central Equatorial Africa, PLO decreases more than its relationship with PLT. This is confirmed by the trend in the temporal evolution of PLO/PLT anomalies (Fig. 6b), which shows a continuous decline. In contrast, for northeast Brazil the trend of anomalies of PLO/PLT is positive, confirming that PLO decreases less than PLT. The results confirm for all four regions that trends in tropical PERA-I are controlled by increases / decreases in the oceanic component of 


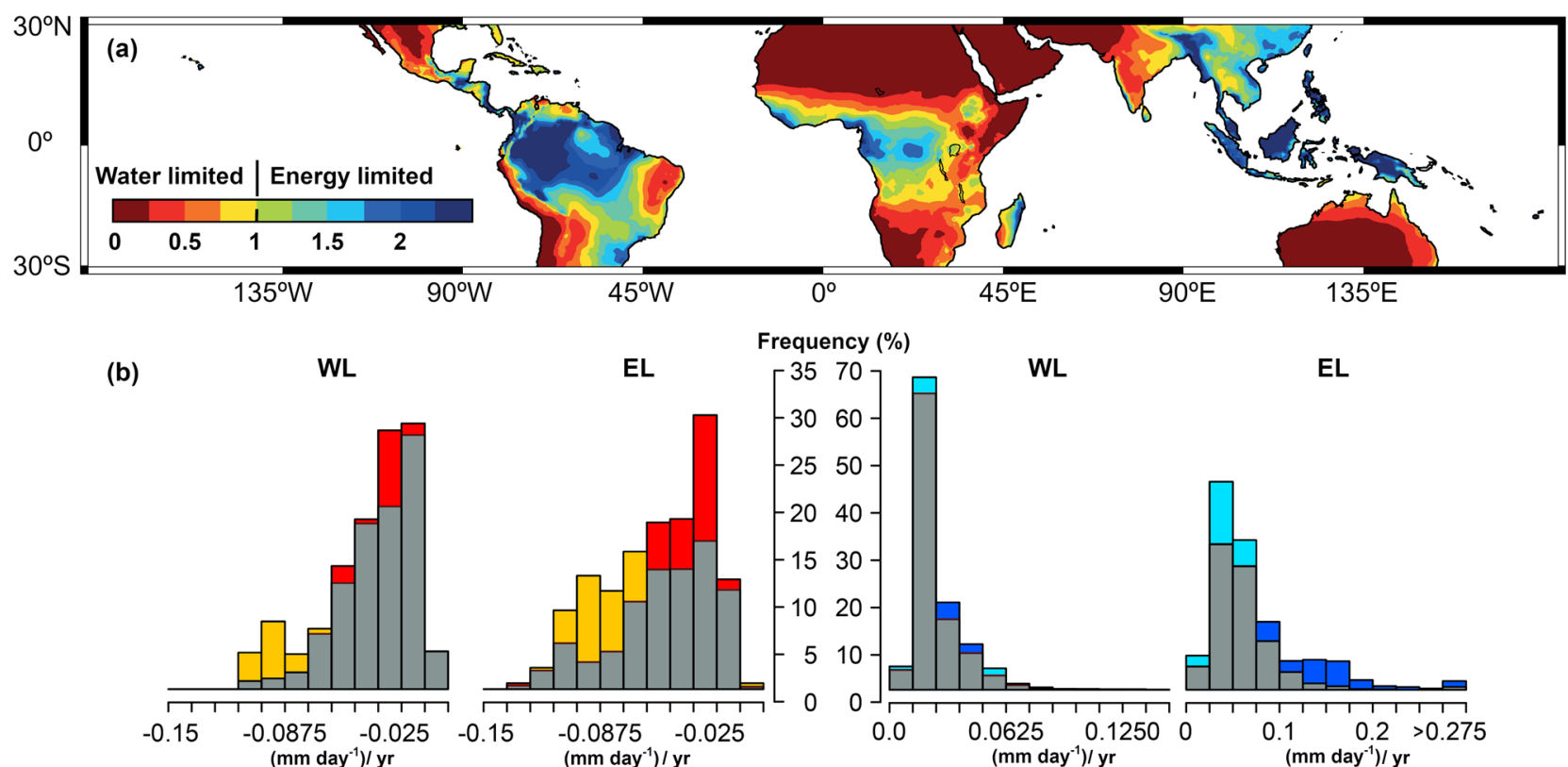

Fig. 5 Relationship between tropical PLO and PLT trends for water- and energy-limited regions. a Annual global distribution of energylimited (EL) and water-limited (WL) areas calculated as the long-term (1980-2015) annual average Precipitation/annual average Potential Evapotranspiration ratio from CRU TS v. $4.03^{34}$ at a resolution of $0.5^{\circ}$. b Histogram of PERA-I trend frequencies for the four different areas defined in Fig. 4a. Time period 1980-2015.

precipitation, corroborating all the findings and suggesting a potential cause of the drought seen in previous decades in Central Equatorial Africa ${ }^{39,47}$ and Northeast Brazil $^{48,49}$, or the recent intensification of the extremes of flooding in the Amazon ${ }^{50}$.

\section{DISCUSSION}

Our results are based on a Lagrangian approach that allows the precipitation to be separated into that where the origin is oceanic and that where the origin is over the continents. In global terms, the percentage of ocean precipitation has already increased in the current climate (1980-2016), with the increase in the tropical regions being especially large (Fig. 2). These results are in line with the intensification of the hydrological cycle with global warming, and with the support of thermodynamic considerations, this leads to an increase in moisture transport from the main sources, where evaporation exceeds precipitation and which are generally located over the oceans, towards the main sinks, where precipitation exceeds evaporation and which are largely located over the continents. A statistical relationship is also apparent between the precipitation and the percentage of precipitation of oceanic origin in tropical regions, where both have experienced upward trends $^{23,51}$. Our results show an increase of $1.15 \%$ per decade, of similar magnitude to the trend in tropical precipitation ${ }^{52}$, which results in a balance between a very high positive trend in the wettest regions (about $2.8 \%$ per decade) with a lower negative trend in the driest regions (about $-1.3 \%$ per decade). Our analysis shows that the percentage of precipitation of oceanic origin increases for wet regions, with a positive trend in precipitation, and decreases in dry regions with a negative trend in precipitation, mainly due to the greater reduction in precipitation of oceanic origin compared with the continental reduction. This suggests that in tropical regions at least, where the relationship between moisture transport and precipitation is more direct, the trends in precipitation are controlled by the oceanic vs. the terrestrial source. Both main results indicate a clear need for a more in-depth study of moisture transport and its changes, to allow a better understanding of precipitation trends in the context of a changing climate, and to give a physical basis for modelled changes in precipitation for future climate scenarios. This will be especially relevant for understanding regional changes in precipitation that are dominated by changes in moisture transport, with a primary focus on areas of monsoon rainfall, whose intensity is strongly dependent on moisture transport.

\section{METHODS}

Data and Lagrangian approach

We use the oceanic (PLO) and terrestrial (PLT) components of precipitation derived from the estimation undertaken by Nieto and Gimeno ${ }^{25}$ for 1980 to 2015 , on an annual basis with a spatial resolution of $0.25^{\circ}$. The two components result from calculating precipitation at each grid point from moisture whose origin is fully oceanic for PLO and fully continental for PLT. The calculation is undertaken by computing the outputs of the Lagrangian FLEXPART v9.0 mode $\left.\right|^{36,37}$ forced by ERA- $\left.\right|^{26}$ data from the ECMWF. This model has a central role in the analysis of moisture transport and has been used with great success in a number of studies. It is used to compute the trajectories of individual atmospheric air masses (namely particles) and the changes in several variables can be analysed, fed by ERA-I data. For studies of moisture transport, the key data are 3D winds and specific humidity. By adding the changes in specific humidity every $6 \mathrm{~h}$ for each particle over a given area, it is possible to estimate E-P, the total budget of atmospheric humidity, with $\mathrm{E}$ being evaporation and $\mathrm{P}$ precipitation. Following the air masses forwards in time, negative values of E-P show sinks for the moisture for precipitation from a given source. The approach of Nieto and Gimeno ${ }^{25}$ yields the gridded optimal integration times (in days) for the best approximation of precipitation for three precipitation databases ${ }^{53}$ : ERA-I, GPCP and MSWEP. To achieve this, for each grid the sum of PLO and PLT, hereafter PL, for different integration times (from 1 to 15 days) is compared with the precipitation values from the three reanalyses, and when the values show a minimum difference Nieto and Gimeno ${ }^{25}$ assume this to be the optimal integration time ${ }^{53}$. Errors are thus minimised if the Lagrangian approach is adjusted to these values for each grid. Based on these values of gridded optimal integration, the contribution of the oceanic and terrestrial sources to precipitation (PLO and PLT, respectively) is calculated. For further information on the approach used see the full description given in Nieto and Gimeno ${ }^{25}$. The percentage of oceanic precipitation is calculated as the percentage of PLO compared with PL.

Areas in Fig. 4 were selected by taking those regions where PERA-I showed significant interannual trends at the $95 \%$ level in the tropical band $30^{\circ} \mathrm{N}-30^{\circ} \mathrm{S}$, where the correlation was very high between the annual 
(a)
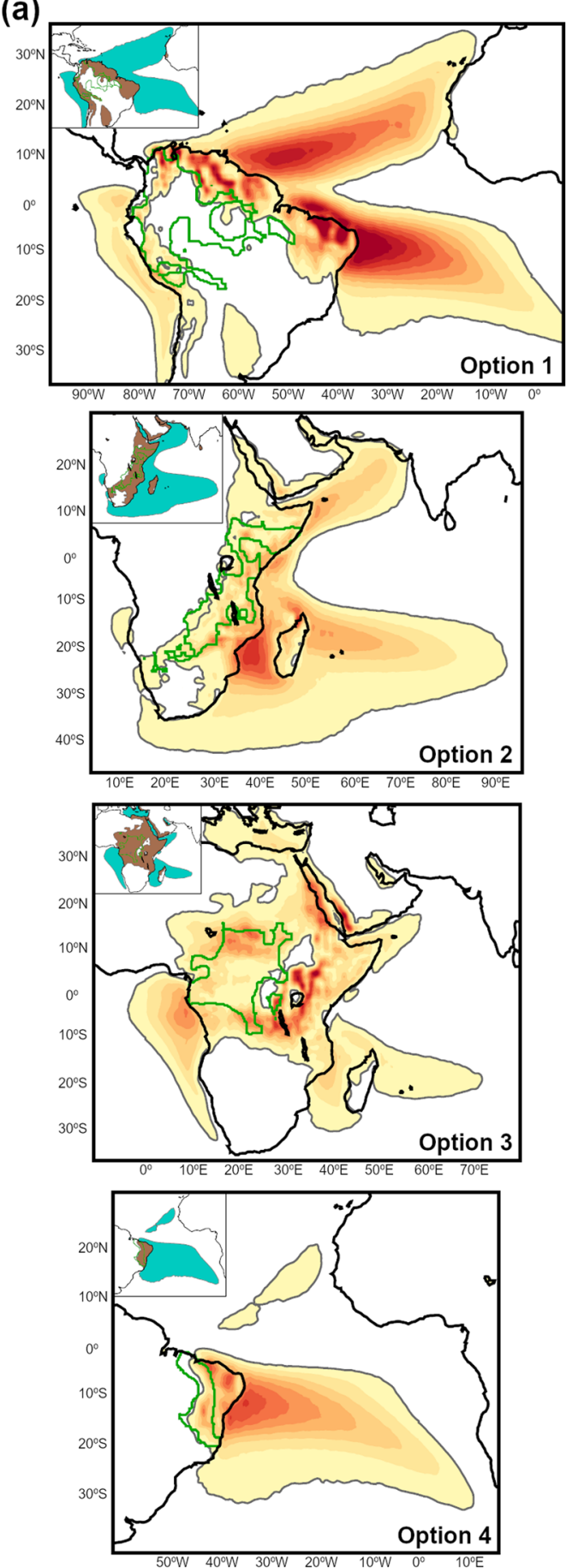

$(E-P)>0 \quad(\mathrm{~mm} / \mathrm{day})$

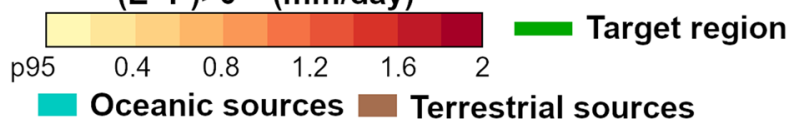

(b)
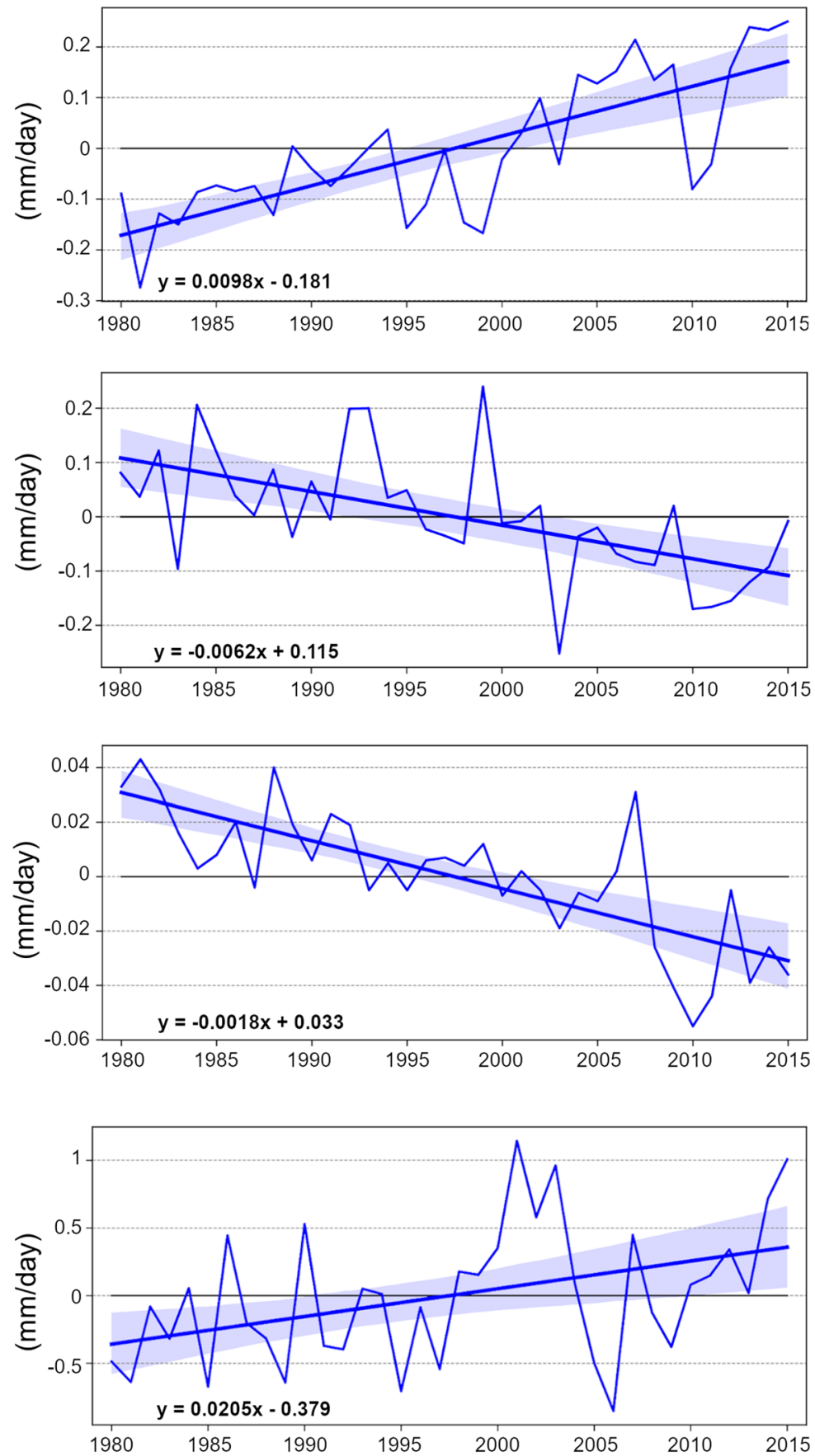

Target region

Anomaly ratio PLO95/PLT95

Fig. 6 Oceanic and terrestrial moisture sources for selected tropical regions. a Oceanic and terrestrial moisture sources defined as the 95th percentile from the annual $(E-P)>0$ values after integration over the optimal number of days of transport as defined by Nieto and Gimeno 25 for each subregion. $\mathbf{b}$ Trends in the anomalies of the ratio between $\mathrm{PLO}_{95}$ and $\mathrm{PLT}_{95}$ being $\mathrm{PLO}_{95}$ the $(\mathrm{E}-\mathrm{P})<0$ over the target region computed for air masses tracked forwards in time from major oceanic sources and PLT $_{95}$ from major continental moisture sources. The 95 percent confidence interval for the trends are indicated using the shaded bands.

percentage of ocean precipitation of the ocean precipitation and the PERAI for the period 1980-2015 (Pearson correlation coefficient of 0.70 at the $99 \%$ level). The division of these areas into four categories corresponds to different combinations in the ratio of trends in PLO and PLT. The annual tropical distribution of energy-limited (EL) and water-limited (WL) areas in Fig. 5 were calculated as the long-term (1980-2015) annual average Precipitation/annual average Potential Evapotranspiration ratio from CRU TS v. 4.03 at a resolution of $0.5^{\circ 34}$. 
Moisture source regions in Fig. 6 were identified using a threshold defined by the value of the 95th percentile from the annual $(E-P)>0$ values after integration over the number of days of transport defined by Nieto and Gimeno $^{25}$ for each subregion. Once identified, the pattern was divided into continental or oceanic, and air parcels from each of the two moisture sources were tracked forwards in time, which enabled us to compare their moisture contributions to precipitation $((E-P)<0)$ from major oceanic sources $\mathrm{PLO}_{95}$ and continental ones $\mathrm{PLT}_{95}$, as well as their trends.

\section{Statistical significance}

$P$-values of below 0.05 were used to estimate the statistical significances of the Pearson correlation coefficients and trends, calculated using the $t$-test. The $t$-test was also used to determine whether the regression slope (trend) of the percentage contribution of the PLO to PL series, both for each latitudinal band and globally, was significantly different from the regression slope of the percentage contribution of PLO to PL in regions where the ERA-Interim trend agrees with GPCP and CRU within the same latitudinal bands and globally, at a 0.05 significance level. A z-test ${ }^{54}$ with a 0.05 significance level was used to compare the distributions of the trends in PLO and PLT in Figs. 4 and 5.

\section{Limitation of the study}

This study has a number of limitations, the first being imposed by the limitations of the ERA-Interim reanalysis used to reproduce the precipitation pattern and its trends. Because the source data in the Lagrangian approach is ERA-I, it cannot be expected that the result of selecting the oceanic component of the precipitation will result in any improvement when both components are added together, compared with the precipitation from the reanalysis. In particular, and related to trends, Simmons ${ }^{55}$ discussed how global trends in the number of assimilated satellite radiances can produce trends in land precipitation. Other studies have also shown that the trends in continental precipitation have substantial bias in certain regions, such as parts of Asia ${ }^{56}$ (and references therein), divergent values in northwest Australia where observations have shown an upward trend, and that the accuracy of the ERA-Interim hydrological cycle is poor over much of Africa due to the lack of assimilated observational data there ${ }^{57}$ (and references therein), for instance it has been shown that ERA-Interim captured the drought in Congo in recent decades, but showed an opposite trend in Sahel and East Africa $^{39}$. Therefore, our finding that both the oceanic and terrestrial components increase in regions of increasing ERA-interim precipitation and decrease in regions of decreasing ERA-interim precipitation might seem inconsistent in areas where the forcing data (precipitation in ERAinterim) is at odds with reality, for instance in northwest Australia. The second limitation is imposed by the method used. The Lagrangian approach was developed to achieve a balance between evaporation and precipitation. This simplified version of our approach only takes values in regions and times where this E-P balance is negative to define precipitation and thus compare it with precipitation obtained from various reanalysis data ${ }^{25}$. Although the error is minimal for large temporal and spatial scales such as those used in this study, care must be taken when generalising the results for small spatial scales. Finally, the number of years of the analysis (37) represents a limitation when considering the trends that result from these calculations.

\section{DATA AVAILABILITY}

The data that support the findings of this study are available from the corresponding author upon reasonable request.

Received: 5 February 2020; Accepted: 2 July 2020;

Published online: 24 July 2020

\section{REFERENCES}

1. Intergovernmental Panel on Climate Change (IPCC). Climate Change 2014: Impacts, Adaptation, and Vulnerability. Part A: Global and Sectoral Aspects (eds. Pachauri, R. K. \& Meyer, L. A.) (Cambridge University Press, Cambridge, United Kindom and New York, NY, USA, 2014).

2. Hegerl, G. C. et al. Causes of climate change over the historical record. Environ. Res. Lett. 14, 123006 (2019).
3. Sun, Q. et al. A review of global precipitation data sets: data sources, estimation, and intercomparisons. Rev. Geophys. 56, 79-107 (2018).

4. Hegerl, G. C. et al. Challenges in quantifying changes in the global water cycle. Bull. Am. Meteor. Soc. 96, 1097-1115 (2019).

5. Trenberth, K. E. Changes in precipitation with climate change. Clim. Res. 47, 123-138 (2011).

6. Gimeno, L. et al. Oceanic and terrestrial sources of continental precipitation. Rev. Geophys. 50, RG4003 (2012).

7. Gimeno, L. et al. Atmospheric moisture transport and the decline in Arctic Sea ice. WIREs Clim. Change 10, e588 (2019).

8. Gimeno, L. et al. On the origin of continental precipitation. Geophys. Res. Lett. 37, L13804 (2010).

9. Gimeno, L. et al. Influence of the intensification of the major oceanic moisture sources on continental precipitation. Geophys. Res. Lett. 40, 1443-1450 (2013).

10. Manabe, S. \& Wetherald, R. T. On the distribution of climate change resulting from an increase in $\mathrm{CO} 2$ content of the atmosphere. J. Atmos. Sci. 37, 99-118 (1980).

11. Allen, M. \& Ingram, W. Constraints on future changes in climate and the hydrologic cycle. Nature 419, 228-232 (2002).

12. Held, I. M. \& Soden, B. J. Robust responses of the hydrological cycle to global warming. J. Clim. 19, 5686-5699 (2006).

13. O'Gorman, P. A. Contrasting responses of mean and extreme snowfall to climate change. Nature 512, 416-418 (2014).

14. Chou, C. et al. Evaluating the "Rich-Get-Richer" mechanism in tropical precipitation change under global warming. J. Clim. 22, 1982-2005 (2009).

15. Greve, P. et al. Global assessment of trends in wetting and drying over land. Nat. Geosci. 7, 716-721 (2014).

16. Byrne, M. P. \& O'Gorman, P. A. The response of precipitation minus evapotranspiration to climate warming: why the "Wet-Get-Wetter, Dry-Get-Drier" scaling does not hold over land. J. Clim. 28, 8078-8092 (2015).

17. Huang, J. et al. Accelerated dryland expansion under climate change. Nat. Clim. Change 6, 166-171 (2016).

18. Findell, K. L. et al. Rising temperatures increase importance of oceanic evaporation as a source for continental precipitation. J. Clim. 32, 7713-7726 (2019).

19. Seager, R. \& Naik, N. A mechanisms-based approach to detecting recent anthropogenic hydroclimate change. J. Clim. 25, 236-261 (2012).

20. Collins, M. et al. Long-term climate change: Projections, commitments and irreversibility, in Climate Change 2013: The Physical Science Basis. Contribution of Working Group I to the Fifth Assessment Report of the Intergovernmental Panel on Climate Change (Cambridge University Press, Cambridge, United Kingdom and New York, NY, USA. 2013).

21. Chadwick, R. et al. Large rainfall changes consistently projected over substantial areas of tropical land. Nat. Clim. Change 6, 177-181 (2016).

22. Donat, M. et al. More extreme precipitation in the world's dry and wet regions. Nat. Clim. Change 6, 508-513 (2016).

23. Adler, R. F. et al. Global precipitation: means, variations and trends during the satellite era (1979-2014). Surv. Geophys. 38, 679-699 (2017).

24. Gimeno, L. et al. Recent progress on the sources of continental precipitation as revealed by moisture transport analysis. Earth-Sci. Rev. 201, 103070 (2020).

25. Nieto, R. \& Gimeno, L. A database of optimal integration times for Lagrangian studies of atmospheric moisture sources and sinks. Sci. Data 6, 1-10 (2019).

26. Dee, D. P. et al. The ERA-Interim reanalysis: configuration and performance of the data assimilation system. Q. J. R. Meteorol. Soc. 137, 553-597 (2011).

27. Huffman, G. J. et al. The Global Precipitation Climatology Project (GPCP) combined precipitation dataset. Bull. Am. Meteor. Soc. 78, 5-20 (1997).

28. Adler, R. F. et al. The Version 2 Global Precipitation Climatology Project (GPCP) monthly precipitation analysis (1979-Present). J. Hydrometeor. 4, 1147-1167 (2003).

29. Beck, H. E. et al. MSWEP: 3-hourly $0.25^{\circ}$ global gridded precipitation (1979-2015) by merging gauge, satellite, and reanalysis data. Hydrol. Earth Syst. Sci. 21, 589-615 (2017).

30. Dunne, J. P. et al. GFDL's ESM2 Global Coupled Climate-Carbon Earth system models. Part I: physical formulation and baseline simulation characteristics. J. Clim. 25, 6646-6665 (2012).

31. Dunne, J. P. et al. GFDL's ESM2 Global Coupled Climate-Carbon Earth system models. Part II: carbon system formulation and baseline simulation characteristics. J. Clim. 26, 2247-2267 (2013).

32. van der Ent, R. J. et al. Contrasting roles of interception and transpiration in the hydrological cycle-Part 2: moisture recycling. Earth Syst. Dynam 5, 471-489 (2014).

33. Simmons, A. J. et al. A reassessment of temperature variations and trends from global reanalyses and monthly surface climatological datasets. Q. J. R. Meteorol. Soc. 143, 101-119 (2017). 
34. Harris, I. et al. Updated high-resolution grids of monthly climatic observations the CRU TS3.10 Dataset. Int. J. Climatol. 34, 623-642 (2014).

35. Dirmeyer, P. A. \& Brubaker, K. L. Evidence for trends in the Northern Hemisphere water cycle. Geophys. Res. Lett. 33, L14712 (2006).

36. Stohl, A. \& James, P. A. Lagrangian analysis of the atmospheric branch of the global water cycle. Part I: Method description, validation, and demonstration for the August 2002 flooding in central Europe. J. Hydrometeorol. 5, 656-678 (2004).

37. Frank, A., Seibert, P. \& Wotawa, G. Technical note: the Lagrangian particle dispersion model FLEXPART version 6.2. Atmos. Chem. Phys. 5, 2461-2474 (2005).

38. Beck, H. E. et al. Global-scale evaluation of 22 precipitation datasets using gauge observations and hydrological modeling. Hydrol. Earth Syst. Sci. 21, 6201-6217 (2017).

39. Hua, W. et al. Assessing reanalysis data for understanding rainfall climatology and variability over Central Equatorial Africa. Clim. Dyn. 53, 651-669 (2019).

40. Igel, M. R. \& Biello, J. A. A reconstructed total precipitation framework. npj Clim. Atmos. Sci. 2, 32 (2019).

41. Haghighi, E. et al. Soil and atmospheric controls on the land surface energy balance: a generalized framework for distinguishing moisture-limited and energy-limited evaporation regimes. Water Resour. Res. 54, 1831-1851 (2018).

42. McVicar, T. R. Global review and synthesis of trends in observed terrestrial nearsurface wind speeds: Implications for evaporation. J. Hydrol. 416-417, 182-205 (2012).

43. Miralles, D. G. et al. Contribution of water-limited ecoregions to their own supply of rainfall. Enviro. Res. Lett. 11, 12 (2016).

44. Zemp, D. C. et al. On the importance of cascading moisture recycling in South America. Atmos. Chem. Phys. 14, 13337-13359 (2014).

45. van der Ent, R. J. \& Savenije, H. H. G. Length and time scales of atmospheric moisture recycling. Atmos. Chem. Phys. 11, 1853-1863 (2011).

46. Yang, K., Wang, C. \& Bao, H. Contribution of soil moisture variability to summer precipitation in the Northern Hemisphere. J. Geophys. Res. Atmos. 121, 12, 108-12,124 (2016).

47. Hua, W. et al. Possible causes of the Central Equatorial African long-term drought. Environ. Res. Lett. 11, 124002 (2016).

48. Marengo, J. A., Torres, R. R. \& Alves, L. M. Drought in Northeast Brazil - past, present, and future. Theor. Appl. Climatol. 129, 1189-1200 (2017).

49. Cunha, A. P. M. A. et al. Changes in the spatial-temporal patterns of droughts in the Brazilian Northeast. Atmos. Sci. Lett. 19, e855 (2018).

50. Barichivich, J. et al. Recent intensification of Amazon flooding extremes driven by strengthened Walker circulation. Sci. Adv. 4, eaat8785 (2018).

51. Adler, R. F. et al. Relationships between global precipitation and surface temperature on inter-annual and longer timescales (1979-2006). J. Geophys. Res. 113, D22104 (2008).

52. Allan, R. P. et al. Current changes in tropical precipitation. Environ. Res. Lett. 5, 025205 (2010).

53. Nieto, R. \& Gimeno, L. Optimal integration times for Lagrangian studies of atmospheric moisture sources and sinks [Data set]. Zenodo. https://doi.org/ 10.5281/zenodo.1453842 (2018).

54. Fleiss, J. L., Levin, B. \& Paik, M. C. The Comparison of Proportions from Several Independent Samples: Statistical Methods for Rates and Proportions. Third Edition (John Wiley \& Sons, New York, 2003).

55. Simmons, A. J. et al. Estimating low-frequency variability and trends in atmospheric temperature using ERA-Interim. Q. J. R. Meteorol. Soc. 140, 329-353 (2014).

56. Liu, Z. et al. Evaluation of spatial and temporal performances of ERA-interim precipitation and temperature in Mainland China. J. Clim. 31, 4347-4365 (2018).
57. Agustí-Panareda, A., Balsamo, G. \& Beljaars, A. Impact of improved soil moisture on the ECMWF precipitation forecast in West Africa. Geophys. Res. Lett. 37, L20808 (2010).

\section{ACKNOWLEDGEMENTS}

This work is financially supported by the Spanish Government within the LAGRIMA project (RTI2018-095772-B-I00). R.S. are supported by the Xunta de Galicia (Galician Regional Government) under grant ED481B 2019/070. Partial support was also obtained from the Xunta de Galicia under the Project ED431C 2017/64-GRC Programa de Consolidación e Estructuración de Unidades de Investigación Competitivas (Grupos de Referencia Competitiva) and Consellería de Educación e Ordenación Universitaria. All of them cofunding from the ERDF, in the framework of the Operational Program Galicia 2014-2020.

\section{AUTHOR CONTRIBUTIONS}

L.G. and R.N. designed the study. R.N. and R.S. did the analysis. L.G. and R.N. wrote the paper. All co-authors contributed to the discussion of the results.

\section{COMPETING INTERESTS}

The authors declare no competing interests.

\section{ADDITIONAL INFORMATION}

Supplementary information is available for this paper at https://doi.org/10.1038/ s41612-020-00133-y.

Correspondence and requests for materials should be addressed to L.G.

Reprints and permission information is available at http://www.nature.com/ reprints

Publisher's note Springer Nature remains neutral with regard to jurisdictional claims in published maps and institutional affiliations.

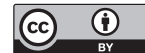

Open Access This article is licensed under a Creative Commons Attribution 4.0 International License, which permits use, sharing, adaptation, distribution and reproduction in any medium or format, as long as you give appropriate credit to the original author(s) and the source, provide a link to the Creative Commons license, and indicate if changes were made. The images or other third party material in this article are included in the article's Creative Commons license, unless indicated otherwise in a credit line to the material. If material is not included in the article's Creative Commons license and your intended use is not permitted by statutory regulation or exceeds the permitted use, you will need to obtain permission directly from the copyright holder. To view a copy of this license, visit http://creativecommons. org/licenses/by/4.0/.

(c) The Author(s) 2020 